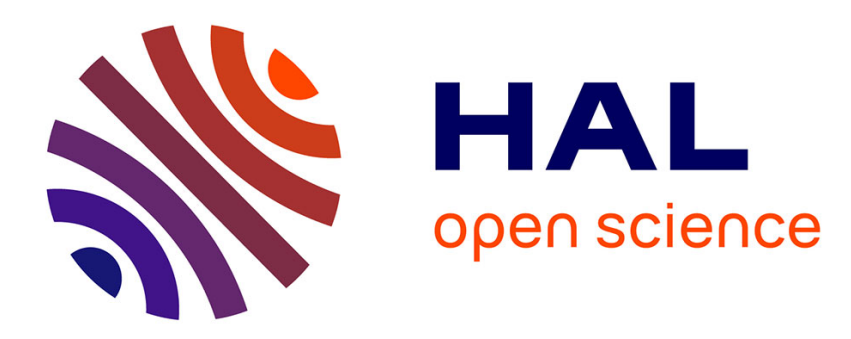

\title{
Introduction: The dynamics of personal networks
}

Claire Bidart, Alain Degenne

\section{To cite this version:}

Claire Bidart, Alain Degenne. Introduction: The dynamics of personal networks. Social Networks, 2005, 27 (4), pp.283-287. halshs-00132981

\section{HAL Id: halshs-00132981 https://shs.hal.science/halshs-00132981}

Submitted on 23 Feb 2007

HAL is a multi-disciplinary open access archive for the deposit and dissemination of scientific research documents, whether they are published or not. The documents may come from teaching and research institutions in France or abroad, or from public or private research centers.
L'archive ouverte pluridisciplinaire HAL, est destinée au dépôt et à la diffusion de documents scientifiques de niveau recherche, publiés ou non, émanant des établissements d'enseignement et de recherche français ou étrangers, des laboratoires publics ou privés. 


\section{Claire Bidart, Alain Degenne ${ }^{1}$ \\ Introduction : The dynamics of personal networks}

The issue of dynamics has been present ever since the earliest research into networks of personal relationships, involving for example questions such as how do relationships come into being, how does the structure of the network influence personal choices and how do personal choices modify this structure? A wide variety of hypotheses have been developed. Some have generated models which are the subject of intense research activity.

These include:

- hypotheses which assume the existence of quasi-universal structural mechanisms: the tendency for ties to be reciprocal, the tendency for transitivity, the tendency for networks to reach equilibrium, etc.

- hypotheses which relate to the preferences of actors: the preference for friends who are similar to us, the preference for reciprocal choices, the preference for the maximum number of relationships etc

- the hypothesis that actors apply the utility maximization principle to their relationships.

- the hypothesis of preferential choice in small world theory: individuals prefer to form ties with those who already occupy a central position in the network.

This list is not exclusive as the field is extremely rich.

These hypotheses are not always tested against reality, but if we assume that the relationships they form within their environments largely determine the approach adopted by actors, it seems very dangerous to make such simple general hypotheses which are independent of context. We are in danger of producing a kind of "relational econometrics" which has no empirical basis and which is removed from concrete behaviours and social contexts.

\footnotetext{
${ }^{1}$ Claire Bidart, Chargée de recherche au CNRS, Laboratoire d'Economie et de Sociologie du Travail, Aix-en-Provence, France. claire.bidart@univmed.fr

Alain Degenne, Directeur de recherche honoraire au CNRS, adegenne $a$ wanadoo.fr.
} 
However, personal networks have a history which shows how the relationship between context and behaviour changes over time. Each network is the result of a process of construction and recomposition that takes place over time. This process is responsible for the form of the network as a result of the addition, disappearance, breaking or formation of ties. Our aim is to observe this temporal dimension by using empirical research to explore the dynamics of networks.

Furthermore, each relationship has its own history. It was created in a specific social environment and developed under specific circumstances. Its course is also the result of a mutual examination of each other by the two parties. Each party has acquired knowledge of the other through their meetings and interactions. Part of this knowledge is obviously shared, but each is liable to interpret it in a different way and put it different uses. The circumstances and the context will play a major role in determining how the relationship will inform or influence these persons' actions.

In order to be able to formulate general hypotheses about individuals' actions and reactions, we therefore feel that great attention should be paid to empirical observations of relationships, in particular as regards how they change over time. Each new interaction changes each party's knowledge of the relationship. The impact of cognitive abstraction and the review process is continual and structurally decisive. A relationship of affinity or a friendship is not monotonic and periods of incomprehension or conflict may occur, but it is characterized by a return to affinity. The present state of the relationship is the outcome of its history and change and it bears marks and features from this past. It is therefore essential to perform a longitudinal survey to study these relationships.

More broadly, the entire personal network in its current form consists of ties which vary with regard to their duration, the period in which they were formed and their history. The network consists of superposed layers of relationships, with varied origins and ages, which are the result of the subject's 
personal history and the various socialization processes the subject engages in in the course of his or her life

If we accept these premises (i.e. the fundamental importance and longitudinal nature of the relationship), there is no absolute distinction between the entire network and the personal network. The latter is merely an instrumentation of the context by the researcher. In some cases the research will observe an evolving community or even construct an experiment; in other cases the researcher will explore individual networks; some research also combines empirical observation and simulation.

The papers presented here mainly attempt to explore, with empirical surveys as a starting point, the changes undergone by personal networks and relationships ${ }^{2}$.

Our aim is also to conserve the temporal dimension of networks, identify the different periods in their history and also try to measure in a precise manner the factors that lead them to change without flattening out the temporal dimension. Too frequently, research into social networks ignores this dimension, as though these networks were timeless and static, emerging from nowhere and never changing. How then can we go beyond a "flat" description of their structure, which is the result of complex layering and interlocking? How is in-depth analysis possible if we have no understanding of how these networks have been constructed and how they have changed?

The personal network is centred on the individual. It bears the marks of this person's history and biography, and also reflects the individual's social characteristics and trajectory in terms of advantages, legacies and statuses. In addition it mirrors the individual's action, reflecting the directions he or she chooses to follow and any changes in them, and his or her projects and way of moving within social space.

This network forms a unit with its own form of coherence. It has its own limits, centre, divisions, internal features and its own specific manner of changing. The personal network is

\footnotetext{
${ }^{2}$ See the special issue of Social Networks: Change in Networks, vol $19 \mathrm{n}^{\circ} 1$, january 1997.
} 
structured around an individual and at the same time belongs to the social circles, i.e. those parts of society, that surround it. It describes the individual's manner of gaining access to, attaching himself or herself to and moving about in society as a whole. It may also reveal the individual's strategies of affiliation.

Thus, our perspective on social networks connects them on the one hand to the individual and his or her biography, and on the other to the social contexts this individual passes through and joins. It therefore attempts to explore relational histories as the elements that form networks in their temporal dimension.

In order to analyze relationships, in particular how they change over time, the ideal situation would be to possess a general theory which would provide us with dimensions and a number of universals which could be used to break the observed relationships up into their constituent parts. Although we lack such a theory, classical sociology affords several approaches for analysis:

- role complementarities,

- identification, i.e. mutual recognition of belonging,

- affinity, i.e. a need for the other individual.

While the topic of role complementarity is frequently covered in surveys conducted in organizations, for example with regard to established roles or requests for advice, its presence is must less frequent in research into personal networks which is conducted on the basis of name generators such as "which persons do you feel particularly close to?" or "which persons are important to you?". This is unfortunate, because the dynamic of day-to-day role interactions deserves better coverage. For example, when reading the research presented here one is struck by the importance of the parent-child or teacher-student relationship. The young persons we have observed at the time of their entry into adult life frequently talk about their relationship with their parents. Those who have children feel that this makes them enter a new 
category, that of parents, and brings them closer to their own parents. However, as yet little emphasis has been given to such role issues.

Shared activities are highlighted in other examples, for example playing football, making music or dancing together. Mentioning such relationships reflects a sense of belonging to the same group and sharing the same identity. This use of phrases like "the football group" and "the people from dancing" also expresses this. The members of these groups are not selected individually, and the subjects do not mention any need to meet them personally, what is involved is belonging to the same group. For this reason we can consider that the activities that are stated to be practiced together are often good indictors of identifications. Nevertheless, personal relationships often develop and break away from these contexts. In France, Michel Grossetti has conducted a very similar survey to Claude Fischer's (1982) placing particular emphasis on the transition between the process of abstraction by which a relationship frees itself from the context in which it came into being and its recontextualization within personal networks. Position in the life cycle and the circles that are frequented seem to be particularly important.

The process by which circles become more specialized and relationships evolve towards multiplexity that Dominique Cardon and Fabien Granjon describe here is interesting as it showcases the fundamental mechanisms involved in the transformation of personal networks. A need for another individual involves two persons and can vary in several ways, as regards the frequency of exchanges, the emotional intensity, the desire for contact as well as the multiplexity of the activities that are performed together. The consideration of geographical distance reveals the specific nature of multiplex relationships of this type which are able to survive physical separation. Christian Licoppe and Zbigniew Smoreda have observed that the telephone provides a means of maintaining ties. The life cycle is present in both exceptional events and daily life and the telephone plays a role in both cases. It is equally important as a 
means of reactivating episodic relationships as as a means of maintain permanent contact. By listening to telephone conversations these scholars show the role played by communications techniques in keeping relationships alive.

The importance of life cycle and the circles in which the subject moves is again apparent in the paper by Alain Degenne and Marie-Odile Lebeaux who analyze the relationships of a cohort of young people whose relationships have been identified and described on three occasions over a nine year span. By relating the origins and shared activities for important relationships with the durability or fragility of the ties, these scholars have shown the way relationships are determined by the circles in which the members move as a function of their age and position in the life cycle.

On the basis of the same survey, Claire Bidart and Daniel Lavenu have identified the different types of process that govern changes in the relational system of young persons by linking these changes to biographical events. Leaving school, attending university, becoming part of couple, gaining access to occupational work and the birth of children are all important times when networks increase or diminish in size and relationships come into being, cease to exist or change in significance.

These papers give an account of the life of relationships as revealed by an investigation centred on the elective dimension and provide important insights into the interplay between belonging to and identifying with groups on one hand and the gaining of independence and the personalization of ties on the other. Here we can see the fundamental role of the life cycle, which determines to a major extent the circles in which people move. Relationships are lived and moulded by experiences rather than rationally chosen or constructed.

Much further work remains to be done in order for the analysis of social networks to be based on an empirically based theory of relationships. 
Furthermore, the dynamic perspective provides fresh opportunities for analysis. First, it allows us to observe a changing reality and identify the processes at work. It invites us to identify various types of changes and to develop tools for identifying and classifying the transformations undergone by these complex systems. As a consequence it reveals the need to isolate the factors that determine these transformations and clarify their source.

This perspective also seems to provide us with a "way of seeing" and represents a heuristic advance. It is easier to understand why something that changes has changed than why something which is static is how it is. Longitudinal analysis of personal networks is therefore of interest from the standpoint of both methodology and problematics. An operational procedure of this type increases the effectiveness of an inductive approach. By observing successive stages and empirically constructing categories and mechanisms of change we are able to identify a variety of descriptors and factors which help us in our task of explaining and interpreting changing reality.

The collection and analysis of empirical data concerning the dynamics of personal networks, about which there are still only a few hypotheses in existence, will enable us to better observe reality and the socio-historical issues that relate to this intermediate social world. A longitudinal perspective of this type has methodological potential for the exploration of the forms and determinants of change. Our desire in this issue was to give priority to these ideas which call for further contributions. 